\title{
LA LABORALIZACIÓN DE LA FUNCIÓN PÚBLICA: LA CESACIÓN DEL VÍNCULO DE LOS FUNCIONARIOS DE LA ATENCIÓN PRIMARIA DE LA SALUD DEPENDIENTES DE UNA CORPORACIÓN MUNICIPAL
}

\author{
Carla Pietroboni Fuster* \\ Abogada
}

\begin{abstract}
RESUMEN: El presente artículo pretende exponer algunos casos en los que resulta dudosa la aplicación del Código del Trabajo para resolver una controversia particular, en especial el caso de la cesación del vínculo de los funcionarios de la Atención Primaria de la salud dependientes de una corporación municipal regidos por la Ley Núm. 19.378 y supletoriamente por la Ley Núm. 18.883.

Palabras clave: Corporación Municipal, Código del Trabajo, Administración Pública, funcionario público.

ABSTRACT: This article pretends to show some cases where it is doubtful the application of the Labor Code to resolve a particular dispute, especially in the case of termination of the bond between officials of the Primary Health, been those individuals subject a municipal corporation governed by Law No 19.378 and additionally by Law No 18.883 .
\end{abstract}

Key words: Municipal Corporation, Labor Code, Public Administration, Official public.

\section{INTRODUCCIÓN}

La llamada laboralización de la función pública es un fenómeno que implica que las relaciones entre un funcionario y la administración del Estado se miren desde una óptica laboralista y, como lógica consecuencia, se pretenda la aplicación de las normas del Código del Trabajo, como asimismo de las instituciones y principios exclusivos de esta rama del Derecho. En el escenario nacional esta es una materia que no ha sido particularmente profundizada por la doctrina. Contrariamente, en el derecho comparado (por ejemplo, Italia, Alemania y España) existen abundantes ejemplos de este cambio laboralizador, tanto en el plano del desarrollo legislativo como en el plano teorético ${ }^{1}$.

$\mathrm{Al}$ amparo de la idea de laboralización, este ensayo pretende mostrar algunos casos en los que es dudosa la aplicación del Código del Trabajo para resolver una controversia particular sobre servicios y, en consecuencia, cómo su aplicación absoluta (esto es, sin respeto al ordenamiento especial diverso) podría desnaturalizar las relaciones reguladas por leyes especiales. En específico el trabajo persigue identificar el marco normativo aplicable a los funcionarios de la atención primaria de salud municipal dependientes de una Corporación Municipal, en concreto las normas que resultan aplicables una vez cesada la relación de servicios

\footnotetext{
* Abogada, Universidad Católica del Norte. Diplomada en Derecho Administrativo de la Pontificia Universidad Católica de Valparaíso. Candidata a Magíster en Derecho de la Empresa y el Trabajo, Universidad Católica del Norte.

1 Véase, entre otros, SAZ CORdero, Silvia del, Contrato laboral y función pública. España: Marcial Pons, 1995; CANTERO MARTíneZ, Josefa, El empleo público: entre el estatuto funcionarial y el contrato laboral. España: Marcial Pons, 2001. SANDE PéreZ-Bedmar, María de, Empleo y prestación de servicios en la Administración pública. España: Lex Nova S.A., 2006.
} 
y, por consiguiente, la procedencia de la aplicación del Código del Trabajo para resolver la controversia. Cabe hacer presente que no nos ocuparemos de los funcionarios de la salud municipal que dependen directamente de una municipalidad (usualmente de las Direcciones de Salud), ya que en dicho caso no hay duda que son funcionarios públicos.

Para el cumplimiento de los objetivos señalados nos referiremos a la jurisprudencia administrativa de la Contraloría General de la República y de la Dirección del Trabajo en cuanto a la posición que sostienen frente al texto de la Ley No 19.378, que señala que dichos funcionarios tienen el carácter de públicos. Además estudiaremos dos sentencias de la Corte de Apelaciones de Antofagasta que tratan la cesación del vínculo de estos funcionarios de forma distinta, arribando a conclusiones diversas frente a la misma situación, y finalmente explicaremos la postura de la Corte Suprema ante la cuestión debatida.

Se han seleccionado las sentencias referidas al caso de los funcionarios regidos por la Ley No 19.378 que se desempeñan en Corporaciones Municipales, la jurisprudencia de la Contraloría General de la República y la de la Dirección del Trabajo relativa a la naturaleza jurídica de los funcionarios en cuestión.

A los efectos del presente trabajo interesa particularmente subrayar aquellas sentencias que se refieren al cese del vínculo de los funcionarios regidos por la Ley No 19.378 que se desempeñan en corporaciones municipales, ya sea aquellas que hacen procedente la aplicación del Código del Trabajo o las que consideran que el vínculo que estudiamos es de carácter estatutario y que, por consiguiente, resulta improcedente la aplicación de dicho cuerpo normativo.

\section{PRECISIONES CONCEPTUALES SOBRE LA LABORALIZACIÓN DE LA FUNCIÓN PÚBLICA}

En nuestro país se ha señalado que:

"La laboralización de la función pública en un sentido fuerte consiste en el total sometimiento a la normativa laboral por parte de los empleados estatales. Es decir, consiste en regular a todos los trabajadores, sean del sector público o del sector privado, a una sola normativa, la del Derecho del Trabajo. En un sentido débil la laboralización de la función pública consiste en la progresiva utilización de normas e instituciones propias del derecho laboral, pero sin que exista una total "huida del derecho administrativo" 2 .

Desde la perspectiva del Derecho español, se ha señalado que la:

"laboralización de funcionarios consiste, propiamente, en la sujeción sobrevenida de los mismos, en su relación de empleo, al régimen contractual-laboral de forma activa -pero manteniendo al mismo tiempo, aunque en suspenso, la relación administrativa estatuta-

\footnotetext{
2 Binder Rosas, Jaime, La laboralización de la Función pública y la nueva gestión pública. Santiago: Boletín Oficial de la Dirección del Trabajo, julio 2002, p. 11.
} 
ria que les une con la Administración-, cuya sujeción se produce, sobre la base de una decisión legal o reglamentaria, y en virtud de la decisión favorable de los funcionarios afectados, con ocasión de la modificación de un sector de la organización pública en el que la relación de trabajo quedan sometidas, asimismo, al derecho de trabajo"3.

La laboralización de la función pública se evidencia principalmente en la aplicación, por mandato legal o judicial, que se hace del Código del Trabajo como norma común a determinados funcionarios. Manifestación de lo anterior es la utilización de instituciones y principios propios del Derecho del Trabajo a relaciones de carácter estatutario regido por normas y principios del Derecho Público.

\section{ANTECEDENTES DE LAS CORPORACIONES MUNICIPALES}

Las corporaciones municipales fueron creadas a partir del DFL No 1-3.063 de 1980 del Ministerio del Interior, que en específico reglamentó el artículo 38 del DL. No 1 - 3.063 de 1979 sobre Rentas Municipales ${ }^{4}$ que establecía la atribución de las municipales de crear este tipo de instituciones, "con la aprobación del Decreto Ley de Rentas Municipales se buscó dotar a las municipalidades de importantes recursos financieros que les permitieran asumir nuevas funciones que hasta entonces estaban radicadas en la administración central" ${ }^{5}$. A partir de la Dictación del mencionado DFL las Municipalidades asumieron la atención de los servicios de salud y educación, entregándole dicho cometido -entre otras ${ }^{6}$ - a las corporaciones municipales, según lo señala el artículo 12. De acuerdo a estas normas, las corporaciones municipales son personas jurídicas de derecho privado regidas por el título XXXIII del Libro I del Código Civil, por sus estatutos y por el mencionado DFL.

La creación este tipo de corporaciones fue posteriormente limitada con la entrada en vigor de la Ley Orgánica Constitucional de Municipalidades. El proyecto de ley de esta nor-

\footnotetext{
3 IzQuierdo Hernández, Francisco; Molina García, Mónica, La Laboralización de los funcionarios públicos. Valencia, España: Editorial Tirant lo Blanch, 1996, p.29.

4 El inciso segundo del artículo 38 del DL. No $1-3.063$ de 1979 señalaba que "[l]as Municipalidades deberán destinar preferentemente los recursos de este fondo -Fondo Común Municipal-, a crear, mantener y prestar servicios a la comunidad local. Además podrán tomar a su cargo servicios que estén siendo atendidos por organismos del sector público o del sector privado, en este último caso atendiéndose al principio de subsidiaridad, como asimismo podrán destinarlos al financiamiento de obras de adelanto local".

5 ANDRADE OlIVARES, Lorenzo, Estatuto Docente en su faceta de estatuto administrativo de derecho público. Santiago: Editorial Thomson Reuters PuntoLex, 2009, p. 6.

6 El artículo 12 del DFL No 1-3063 de 1980 que se refiere a la creación de este tipo de instituciones señala: "[1]as Municipalidades que tomen a su cargo servicios de las áreas de educación, de salud o de atención de menores, para los efectos de la administración y operación de ellos, podrán constituir, conforme a las normas del Título XXXIII del Libro I del Código Civil, con organizaciones de la comuna, interesadas en los servicios referidos, una o más personas jurídicas de derecho privado, o podrán entregar dicha administración y operación a personas jurídicas de derecho privado que no persigan fines de lucro. En los estatutos de las personas jurídicas que constituyan las Municipalidades deberá establecerse que la presidencia de ellas corresponderá al Alcalde respectivo, quien podrá delegarla en la persona que estime conveniente y que el número de directores no podrá ser superior a cinco. Todos estos cargos serán concejiles.

Autorízase a las Municipalidades que otorguen a la administración de los servicios referidos a personas jurídicas de derecho privado para entregarles en comodato los bienes inmuebles destinados a los servicios referidos, ya sean de propiedad de la $\mathrm{Mu}$ nicipalidad o esta los haya recibido, a su vez, en comodato para tales servicios".
} 
ma contenía en el artículo 5 letra h) la atribución de "organizar corporaciones y fundaciones de derecho privado sin fines de lucro, con el único objeto que puedan realizar cometidos relacionados con las materias a que se refiere el artículo $4^{\circ}$. Esta norma fue declarada inconstitucional por el Tribunal Constitucional en la sentencia de fecha 29 de febrero de $1988^{7}$ a propósito del trámite de control de Constitucionalidad del proyecto de Ley Orgánica Constitucional de Municipalidades. Ahora bien se ha dejado muy en claro que las corporaciones creadas con anterioridad no son inconstitucionales ${ }^{8}$.

Actualmente existen más de cincuenta corporaciones municipales de desarrollo. En su mayoría se ocupan de la administración de los establecimientos de educación municipal y de los consultorios de atención primaria de salud ${ }^{9}$. No obstante existen corporaciones municipales que solo cumplen el primero de los fines.

En las corporaciones -en atención a las funciones de administración de la educación y la salud municipal- conviven una serie de trabajadores y funcionarios regidos por diversos cuerpos legales, así tenemos:

a) los profesionales de la educación regidos principalmente ${ }^{10}$ por el Estatuto Docente;

b) los asistentes de la educación dentro de los cuales se encuentran los profesionales no docentes, los paradocentes y los auxiliares de servicios están normados por la Ley No. 19.464 y el Código del Trabajo;

c) los funcionarios de la Salud regidos principalmente ${ }^{11}$ por la Ley No 19.378 ; y, por último,

\footnotetext{
En el considerando veintiuno de la sentencia se explica dicha decisión "[p]or su parte, el señalado artículo $4^{\circ}$ establece las funciones que las municipalidades podrán desarrollar, directamente o con otros órganos de la Administración del Estado. En concordancia con estas normas, el artículo 55, letra g), del proyecto otorga al alcalde, con acuerdo del consejo de desarrollo comunal, la facultad de 'crear, en conformidad a las normas legales vigentes, corporaciones y fundaciones de derecho privado sin fines de lucro para el cumplimiento de las funciones a que se refiere el artículo $4^{\circ}$. Por último, en armonía con esta disposición, el artículo 78, letra i), del proyecto remitido establece que los consejos de desarrollo comunal deberán prestar su acuerdo para la 'creación de corporaciones y fundaciones de derecho privado sin fines de lucro, para el cumplimiento de las funciones señaladas en el artículo 40'; Considerando veinte y dos: “[q]ue de la relación de las normas antes transcritas se infiere que mediante estos preceptos del proyecto se otorga a las municipalidades la atribución de crear corporaciones o fundaciones de derecho privado, sin fines de lucro, con el objeto de realizar las llamadas funciones 'compartidas' que el artículo $4^{\circ}$ atribuye a los municipios. A su vez, se determinan los órganos de estos encargados de adoptar las resoluciones correspondientes para llevar a cabo la referida atribución"; Considerando veinte y tres: "[q]ue esta facultad, en los términos en que se establece, importa otorgar a las municipalidades la atribución de trasladar funciones que le son propias, según el campo de acción que le ha fijado la Constitución, a entidades con personalidad jurídica distinta de ellas. Esta traslación de funciones y atribuciones, en principio, no es constitucionalmente aceptable, por cuanto la Carta Fundamental encarga a las 'municipalidades' la realización de estas funciones públicas, determinadas en el proyecto dentro del marco constitucional de distribución de competencias que se le asignan a los distintos órganos del Estado. En consecuencia, los artículos 5, letra h), 55, letra g), y 78, letra i), del proyecto, al permitir, en forma amplia, que sean otras entidades las que realicen las funciones que son propias de las municipalidades, aun cuando ellas tengan el carácter de 'compartidas', altera esa distribución de competencias e infringe la normativa constitucional".

8 Ver oficio $N^{\circ}$ 554, de 7 de abril de 1988, dirigido al señor Ministro del Interior, posición reafirmada por la Contraloría General de la República.

9 Hoy llamados CESFAM -Centros de Salud Familiar- o CECOF -Centros comunitarios de salud familiar-.

10 La función docente está regulada -además- por una infinidad de reglamentos y leyes especiales que se refieren a artículos específicos de alguna ley. El entramado normativo de este sector es complejo e innumerable.

11 Aplica lo señalado para el sector docente.
} 
d) los trabajadores que no están sujetos a un estatuto diverso que se rigen por el Código del Trabajo.

\section{MARCO NORMATIVO DE LOS FUNCIONARIOS DE LA ATENCIÓN PRIMARIA DE LA SALUD MUNICIPAL DEPENDIENTES DE UNA CORPORACIÓN MUNICIPAL}

El marco regulatorio de los funcionarios de la salud dependientes de este tipo de instituciones está integrado principalmente por el Estatuto de la Atención Primaria contenido en la Ley No 19.378 (D.O. 13.04.1995) norma que establece el régimen del personal de la Atención Primaria de Salud Municipal, fijando, entre otras, la dotación y jornada de trabajo, sus derechos, las remuneraciones, la carrera funcionaria, el término de la relación laboral, el financiamiento y la administración. De manera supletoria -por así indicarlo el artículo 4 de la ley- rigen las disposiciones de la Ley No 18.883, que corresponde al Estatuto Administrativo para funcionarios municipales.

El artículo 1 de la Ley No 19.378 fija el ámbito de aplicación, señalando que sus normas rigen a los establecimientos de atención primaria de salud cuya administración se encuentra traspasada a las municipalidades de acuerdo a lo dispuesto en el DFL. No 1-3.063, de 1980; a los que crearán las municipalidades, a los traspasados con posterioridad por los Servicios de Salud y a los que por cualquier causa se incorporarán a la administración municipal. Luego, la relación del funcionario de la Atención Primaria de Salud y la Corporación Municipal a la que pertenece es de carácter estatutaria, conformándose dicho estatuto de derecho público, en primer lugar, por las normas de la Ley No 19.378 y, supletoriamente, por el Estatuto Administrativo de los Empleados Municipales que contiene la Ley No 18.883, salvo en lo relacionado con concursos, jornada de trabajo, feriados y permisos, materias en que se aplican supletoriamente las disposiciones pertinentes de la Ley No 15.076.

En consecuencia, las disposiciones de la Ley No 19.378 permiten sostener estas dos afirmaciones: a) los funcionarios que desarrollan sus funciones en la atención primaria de salud municipal y que dependen de una corporación son funcionarios públicos, por así indicarlo la letra expresa del artículo $4^{\circ}$ de la Ley y la historia fidedigna de su establecimiento ${ }^{12}$ y b) el régimen jurídico que une a estos funcionarios con la corporación de la que dependen es de carácter estatutario.

\footnotetext{
12 Segundo trámite, informe de la Comisión, en: Historia de la Ley No 19.378. Compilación de textos oficiales del debate parlamentario. Santiago, 1997, pp. 448 y ss. "Los representantes del ejecutivo hicieron presente que no correspondía la aplicación supletoria del Código del Trabajo, ni la negociación colectiva, por cuanto las ideas matrices del proyecto contenidas en el Mensaje expresan que en el Título II se contemplan las normas generales del régimen laboral, precisándose que la legislación supletoria de las normas del Estatuto es la contenida en la Ley No 18.883, Estatuto de los Funcionarios Municipales, ya que los primeros comparten la misma naturaleza jurídica de estos y, por tanto, no estarán afectos a las normas sobre negociación colectiva.

Añadieron que, además, la naturaleza jurídica de estos trabajadores es la de funcionarios del sector público, puesto que ejercen una función pública.

Por último, el estatuto laboral propuesto en el proyecto está implementando por primera vez un sistema de carrera funcionaria con distintas categorías y niveles de remuneraciones. En este sistema es incompatible una estructura que contemple aplicar supletoriamente el Código del Trabajo y, adicionalmente, la negociación colectiva, dado que la asignación de recursos para las remuneraciones de estos trabajadores establece sueldos base y determinadas asignaciones"
} 
Pese al texto expreso de la ley, tanto la Contraloría como la Dirección del Trabajo sostienen que no son funcionarios públicos, atendiendo fundamentalmente al carácter privado de estas instituciones.

\section{EMPLEADOS DE LA SALUD DEPENDIENTES DE CORPORACIONES MUNICIPALES, ¿FUNCIONARIOS O TRABAJADORES?}

Se ha discutido latamente si las personas que al alero de una corporación trabajan en la atención primaria de salud son trabajadores o funcionarios públicos. La contienda se produce en general por la naturaleza jurídica de las corporaciones municipales y en particular por la norma del artículo 4 de la Ley No 19.378, que en su inciso $1^{\circ}$ y $2^{\circ}$ sostiene: "En todo lo no regulado expresamente por las disposiciones de este Estatuto, se aplicarán, en forma supletoria, las normas de la Ley No 18.883, Estatuto de los Funcionarios Municipales. El personal al cual se aplica este Estatuto no estará afecto a las normas sobre negociación colectiva y, sobre la base de su naturaleza jurídica de funcionarios públicos, podrá asociarse".

La primera diferencia en el tratamiento que decidió el legislador respecto de los funcionarios de la atención primaria de salud dependientes de una corporación no se refiere al principal cuerpo normativo que los rige, ya que es muy común que se establezcan estatutos determinados frente a actividades particulares. La peculiaridad se nota en la norma que los rige de manera supletoria como ya lo dijimos, la Ley No 18.883. El Estatuto Administrativo para Funcionarios Municipales, entramado normativo que inevitablemente trae aparejada una diferencia con el resto de los trabajadores de una corporación a los que se les aplica el Código del Trabajo ya sea como norma principal o supletoria. En consecuencia, por mandato legal no se aplicaría de forma supletoria el Código del Trabajo. Un segundo elemento distintivo lo entrega el inciso $2^{\circ}$ del artículo 4 que se refiere a la negociación colectiva, precisando que las normas sobre esta materia no les resultan aplicables por su naturaleza jurídica de funcionarios públicos.

Así ya se vislumbra el fondo del problema: la existencia de funcionarios públicos -según texto expreso de la ley- dependientes de una corporación de derecho privado, regida por las normas del Código Civil.

La Contraloría General de la República, ha sostenido en varios dictámenes que:

"Este organismo de control se encuentra impedido de intervenir en relación con situaciones laborales acaecidas en las corporaciones a que se refiere el artículo 12 del Decreto con Fuerza de Ley No 1-3.063, de 1980, del Ministerio del Interior, por cuanto, como estas como constituyen personas jurídicas de derecho privado, el personal que en ellas labora no reviste la condición de funcionarios municipales, correspondiendo, en consecuencia, a la Dirección del Trabajo la fiscalización del cumplimiento de la Ley No 19.378 en tales entidades".

Agrega el ente contralor:

"En efecto, la circunstancia que la norma aludida regule, en lo que interesa, la relación laboral de los trabajadores en comento -del sector particular-, consagrando sus 
derechos y deberes y estableciendo a su respecto un sistema de carrera funcionaria, no puede entenderse por ello que el legislador haya pretendido asignar a ese personal la calidad de servidores públicos, porque tal conclusión resultaría inconciliable con la naturaleza jurídica de personas de derecho privado que las entidades administradoras donde laboran deben necesariamente revestir, en virtud de lo previsto en el citado artículo 12 (aplica dictámenes $\mathrm{N}^{\circ}$ s 29.730, de 1995, 18.547, de 1996 y 44.103, de $2006 " 13$.

Ha señalado también: "Esas corporaciones son personas jurídicas de derecho privado y sus trabajadores son empleados del sector privado, estando fuera de la fiscalización de Contraloría, pues ella solo tiene atribuciones respecto a los organismos de la administración del Estado y entidades que una ley orgánica constitucional someta a su control"14.

De la jurisprudencia administrativa citada fluye que, para determinar si un empleado es funcionario público, es preciso atender al lugar donde este labora y no a la función propiamente tal. Tratándose de las mismas funciones, del mismo estatuto aplicable, tanto principal como supletorio (además del texto expreso de la ley que indica que dichos empleados tienen la naturaleza de funcionarios públicos), la Contraloría considera que los dependientes de la Dirección de Salud en una Municipalidad sí son funcionarios públicos, y por el contrario los dependientes de un Corporación Municipal son trabajadores privados ${ }^{15}$.

Por su parte la Dirección de Trabajo, adhiriendo a la jurisprudencia de la Contraloría (a través de referencias expresas) ha indicado ${ }^{16}$ que:

"Según el tenor de la norma transcrita, se desprende que el personal afecto a la Ley No 19.378 y su Reglamento está impedido de negociar colectivamente, y se le reconoce la naturaleza jurídica de funcionarios públicos para los efectos de organizarse en el marco de las disposiciones de la Ley No 19.296 de 1994, que Establece Normas sobre Asociaciones de Funcionarios de la Administración del Estado.

Sin embargo, la naturaleza jurídica de funcionarios públicos que se reconoce a dicho personal, no tiene el alcance propio que se atribuye a quienes laboran para un organismo público, por cuanto y como lo ha expresado la Contraloría General de la República en dictamen No 29730, de 21.09.95, las corporaciones constituidas por las municipalidades 'para administrar establecimiento de "salud en los términos que prevé el artículo 12 del DFL. No 1-3063 de 1980, del Ministerio del Interior, como las instituciones privadas sin fines de lucro a las que se haya entregado dicha administración de acuerdo con el mismo precepto, son entidades de derecho privado', por lo

\footnotetext{
13 Contraloría General de la República, dictamen No 43.720, 16 de septiembre de 2008. Disponible en http://www.contraloria.cl

14 Contraloría General de la República, dictamen No 18.547, 10 de junio de 1996; No 37.260, 8 de agosto de 2008. Disponibles en http://www.contraloria.cl

15 Véase, entre otros, dictámenes de la Contraloría General de la República No 61.847, 26 de diciembre de 2006; No 44.103, 15 de septiembre de 2006; No 35.122, 6 de noviembre de 1995

16 Entre otros, Dirección del Trabajo, dictámenes No 2140/150, 14 de mayo de 1998; No 3994/056, 8 de octubre de 2009; No 1246/69, 18 de abril de 2002; y No 2164/94, 25 de mayo de 2004. Todos disponibles en http://www.dt.gob.cl
} 
que 'no puede atribuirse a dicho personal el carácter de funcionario público' propiamente tal, 'puesto que esta condición solo es atribuible al trabajador que' preste sus servicios para un organismo público. Ello, porque de acuerdo con la historia fidedigna del establecimiento de la ley, el reconocimiento de la naturaleza jurídica de funcionarios públicos en cuestión, solo se concibe en el propósito legislativo de destacar la evidente importancia, urgencia e interés general que representa la atención primaria de salud municipal"17.

Esta suerte de desfuncionarización, por la vía de la jurisprudencia administrativa, es criterio uniforme en la jurisprudencia administrativa de la Contraloría y de la Dirección del Trabajo, doctrina que no atiende a la función propiamente tal para calificar a un trabajador de funcionario público, sino al lugar donde se desarrolla tal actividad. El organismo contralor refuerza su tesis añadiendo:

"que esa conclusión no puede verse afectada por el hecho de que el personal de que se trata disponga de una carrera funcionaria, pueda organizarse según las normas del sector público y que se aplique supletoriamente el Estatuto de los funcionarios municipales, por cuanto "todas y cada una de esas circunstancias no tienen la virtud de cambiar la calidad jurídica de derecho privado que caracteriza a las corporaciones constituidas por las municipalidades y las instituciones que administran operan establecimientos de salud en los términos que prevé el artículo 12 del citado DFL No 1-3063, de 1980, del Ministerio del Interior”.

Esta tesis de la desfuncionarización se aparta de la tesis de cuño administrativista que, para los efectos de aplicar las reglas del derecho público, atiende al servicio desde la función y no desde el órgano. Si bien consideramos que los funcionarios de la salud municipal dependientes de una corporación son funcionarios públicos por una serie de razones que van más allá del servicio que prestan, es innegable que la actividad que desarrollan cumple todas las exigencias para calificarse como servicio público.

A continuación se analizará la cesación del vínculo de los funcionarios de la atención primaria de salud dependientes de una Corporación Municipal.

\section{LA CESACIÓN DEL VÍNCULO}

La discusión sobre la calificación de los funcionarios de la atención primaria de salud no es baladí. Ella tiene incidencia en diversas materias que reglan la relación de esos empleados con la institución de la cual dependen, entre las que resulta determinante la cesación del vínculo. Sobre este último tema el artículo 48 de la Ley No 19.378 señala que "[1]os funcionarios de una dotación municipal de salud dejarán de pertenecer a ella solamente por las siguientes causales (...)". Ello significa que las causales que motivan el alejamiento de un funcionario de la salud municipal solo pueden ser aquellas detalladas en el mencionado

17 Dictamen de la Dirección de la Dirección del Trabajo No 6598/298, 28 de noviembre de 1996. 
artículo y cumpliéndose con las exigencias establecidas en la misma norma. Por otra parte, en materia indemnizatoria, el artículo 48 de la Ley No 19.378 contempla una indemnización equivalente al total de las remuneraciones devengadas en el último mes por cada año de servicio en la municipalidad respectiva con un máximo de once años, solo para el caso en que el término de la relación con el funcionario se produzca por aplicación de la causal de la letra i) del artículo 48 es decir "[d]isminución o modificación de la dotación, según lo dispuesto en el artículo 11 de la presente ley". En definitiva, para el resto de las causales que justifican o motivan el término de la relación del funcionario con la corporación, el legislador no previó indemnizaciones de ninguna especie.

Conforme a lo ya expuesto, en materia de terminación del vínculo y de las indemnizaciones subsecuentes, no cabría la aplicación del Código del Trabajo como parte del marco regulatorio de la actividad de los funcionarios de la atención primaria de salud dependientes de una corporación municipal ${ }^{18}$. Esta conclusión, como se explicará más adelante, no se ve alterada por la difundida tesis (usualmente invocada en tribunales) que propone la aplicación supletoria del Código Laboral a partir de una norma contenida en el Estatuto Administrativo para los funcionarios municipales. Nos referimos a la tesis que resulta de la lectura conjunta del inciso $2^{\circ}$ del artículo $3^{\circ}$ de la Ley No $18.883^{19}$ con el artículo $1^{\circ}$ del Código del Trabajo ${ }^{20}$.

\section{SOBRE LA PROCEDENCIA DE LA [ULTRA] APLICACIÓN SUPLETORIA DEL CÓDIGO DEL TRABAJO}

La cuestión radica en determinar si procede o no la aplicación supletoria del Código del Trabajo para el caso del término de la relación de los funcionarios de la atención primaria de salud dependientes de una corporación municipal. Prima facie se debería optar por una respuesta negativa por cuanto existe una norma expresa -artículo 4 de la Ley No 19.378- que señala que la norma supletoria es la Ley No 18.883.

Los tribunales de la instancia suelen aplicar los principios del Derecho del Trabajo a los vínculos estatutarios como el que estudiamos. Por ejemplo, aplican la transformación del contrato a plazo fijo a indefinido considerando las renovaciones que ha sufrido el primero, haciendo caso omiso de norma expresa que señala que la única forma de ser parte de la dotación y por lo tanto ejercer el cargo en calidad de titular con un contrato de carácter indefinido es haberse adjudicado un concurso público, o que una ley particular así lo determine ${ }^{21}$.

La tendencia de los juzgados del trabajo contrasta, en general, con la jurisprudencia

\footnotetext{
18 Dirección del Trabajo, dictamen No 6598/298, 28 de noviembre de 1996, que señala: "por consiguiente, el estatuto de los funcionarios municipales se aplica supletoriamente al personal regido por la Ley No 19.378, no obstante el carácter de derecho privado que tienen las corporaciones que administran y operan la atención primaria de salud municipal, y el Código del Trabajo solo es aplicable a la situación contemplada por el artículo $6^{\circ}$ transitorio de la ley citada”.

19 "El personal que se desempeñe en servicios traspasados desde organismos o entidades del sector público y que administre directamente la municipalidad se regirá también por las normas del Código del Trabajo".

20 "Con todo, los trabajadores de las entidades señaladas en el inciso precedente se sujetarán a las normas de este Código en los aspectos o materias no regulados en sus respectivos estatutos, siempre que ellas no fueran contrarias a estos últimos".

21 Primer Juzgado de Letras del Trabajo de Santiago, 15 de octubre de 2009. RIT No 0-103-2009, "Morales Maldonado, Verónica con Corporación de Educación y Salud de Las Condes”. Disponible en http://www.poderjudicial.cl
} 
de los tribunales superiores de justicia. Estos últimos han resuelto en favor de la tesis según la cual no procede la aplicación del Código del Trabajo ${ }^{22}$.

Una buena muestra de las tesis que se enfrentan puede encontrarse en la jurisprudencia de la Corte de Apelaciones de Antofagasta. En dicho tribunal dos casos similares se han fallado de manera distinta por la vía de la nulidad. En un caso se aplicó como norma supletoria el Código del Trabajo por considerar que se está en presencia de un vínculo laboral y en el otro caso se abstuvo de dicha aplicación por estimar que el vínculo que une a un funcionario de la salud con la corporación municipal es de carácter estatutario.

En el primer fallo ${ }^{23}$, la Corte resuelve:

"Que el artículo 4 de dicho cuerpo legal prescribe que en todo lo no regulado expresamente por las disposiciones de este Estatuto se aplicará en forma supletoria las normas de la Ley No 18.883, Estatuto de los Funcionarios Municipales. Entonces, es esta última ley, y no el Código del Trabajo, la normativa que rige al personal de los establecimientos de Atención Primaria de Salud Municipal, criterio por demás manifestado en fallos recientes de la Excma. Corte Suprema ${ }^{24}$. (Considerando sexto)".

Abundando en esta idea, el fallo señala que:

"la aplicación supletoria del Código del Trabajo tiene lugar únicamente en los aspectos o materias no reguladas por los estatutos a que ellos están afectos, pero ello es siempre que las normas del código no sean contrarias a tales normas (inciso $3^{\circ} \mathrm{del}$ artículo 1 del Código del Trabajo) (Considerandos sexto y octavo).

Que el artículo 160, del Código del Trabajo es incompatible con las disposiciones establecidas en la Ley No 19.378 y No 18.883 que regulan las causales de expiración de funciones. Tampoco estos cuerpos legales conceden indemnizaciones similares a las previstas en los artículos 162 y 168 para el caso de un despido injustificado" (Considerando noveno).

\footnotetext{
22 En la sentencia autos Rol No 36-2009 pronunciada por la Corte de Apelaciones de Santiago, de fecha 14 de enero de 2010, se señala (Considerando quinto) "[q]ue al razonar de la manera que se viene comentando la sentencia efectivamente ha cometido el error de derecho que señala la recurrente. En efecto, el artículo $3^{\circ}$ de la ley No 19.378 señala que las disposiciones de esta ley se aplicarán a todo el personal que se desempeñe en los establecimientos municipales de atención primaria de salud, como es el caso de autos, agregando el artículo $4^{\circ}$ de la misma legislación que 'En todo lo no regulado expresamente por las disposiciones de este Estatuto, se aplicarán en forma supletoria, las normas de la Ley No 18.883, Estatuto de los Funcionarios Municipales', de manera que no es cierto que el Código del Trabajo sea la norma aplicable a la especie en forma supletoria, pues hay norma expresa -la recién transcrita- que se encarga de regular este tema. Luego, yerra el fallo, infringiendo el citado artículo $4^{\circ}$ de la Ley No 19.378, al hacer aplicable a la especie la normativa laboral común cuando perentoriamente ha de aplicarse el Estatuto Administrativo de los Funcionarios Municipales, contemplado en la Ley No 18.883. En consecuencia, decidir que al haber celebrado la partes varios contratos a plazo fijo ha tornado la relación laboral en indefinida, haciendo así aplicable el inciso cuarto del $\mathrm{N}^{\circ} 4$ del artículo 159 del Código del Trabajo, con todas las consecuencias que ello trae, deviene de la no aplicación del citado artículo $4^{\circ}$ de la Ley No. 19.378”. En contra véase sentencia de la Corte de Apelaciones de Santiago, de fecha 26 de enero de 2011, autos Rol No 7641-2009.

23 Corte de Apelaciones de Antofagasta, 10 de mayo de 2011, autos Rol No 224-2010. "Sornoza García, Robert con Corporación Municipal de Desarrollo Social de Antofagasta. Disponible en http://www.poderjudicial.cl

24 Corte Suprema, 9 de junio de 2010, autos Rol No 1519-10.
} 
"Que el fallo citado en su motivo undécimo señala que el Código Laboral establece un régimen jurídico de naturaleza convencional, que se concreta en contratos dirigidos por normas de orden público que reconocen derechos y beneficios mínimos para los trabajadores y cuya aplicación fiscalizan organismos estatales creados con esa finalidad. (Considerando décimo).

Que en cambio, agrega, el régimen estatutario es de carácter legal, ya que es la ley la que exclusivamente regula la situación de los funcionarios y señala la forma como nace y se extingue su relación con el Estado, este sistema no tiene origen ni naturaleza convencional, ya que es el legislador el que determina por completo los derechos y obligaciones que son afectos de esa relación (Considerando undécimo)".

Cabe hacer presente que la parte recurrente de nulidad no alegó la incompetencia del Tribunal del Trabajo, por cuanto ni la norma principal, ni la norma supletoria establecen un procedimiento para reclamar de la causal aplicada para terminar la relación del funcionario. En este caso se estimó que la aplicación del procedimiento laboral no desnaturalizaría el vínculo, ni la normativa aplicable ya que existe un verdadero vacío legal.

El segundo fallo que estudiamos ${ }^{25}$ es totalmente opuesto al recién citado, por cuanto como vicio fundamental de la sentencia se alega la incompetencia del juez del trabajo. La Corte de Antofagasta rechazó el recurso no solo porque estimó que el Juez de la instancia es perfectamente competente para conocer de la cuestión sub lite, sino que consideró además -según da cuenta el considerando cuarto-:

“[q]ue las normas de las leyes citadas -Ley No 19.378 y Ley No 18.883- no regulan todas las cuestiones jurídicas que se derivan de un contrato de trabajo y que por lo tanto debe aplicarse el artículo 1 inciso $3^{\circ}$ del Código del Trabajo, que expresa: con todo, los trabajadores de las entidades señaladas en el inciso precedente se sujetarán a las normas de este Código en los aspectos o materias no reguladas en sus respectivos estatutos, siempre que ellas no fueran contrarias a la de estos últimos"

En el considerando quinto del fallo se señala:

"Que en caso de autos la actora ha demandado el despido injustificado y el cobro de prestaciones laborales y por lo tanto ambas acciones hay que enmarcarlas en el artículo 420 letra a) del Código del Trabajo por tratarse de cuestiones suscitadas entre empleador y trabajador por aplicación de las normas laborales. Que como señala el sentenciador el artículo 48 de la Ley No 19.378 que regula la terminación de la relación laboral establece causales de término de contrato, estableciendo una indemnización por años de servicio específica (solo para el caso de término de la relación laboral por disminución de la dotación). No se establece entonces una reclamación ante los tribunales de justicia que pueda calificar la errónea o acertada aplicación de la causal

25 Corte de Apelaciones de Antofagasta, 26 de abril de 2011, autos Rol No 19-2011. "Ahumada Barraza, Sandra con Corporación Municipal de Desarrollo Social de Calama”. Disponible en http://www.poderjudicial.cl. 
de despido, debiendo aplicarse supletoriamente -como lo ordena el artículo 1 del Código del Trabajo- la normativa regida por el Código laboral en lo que respecta a despido injustificado e indemnizaciones de perjuicio.

Finalmente en el considerando sexto sostiene:

"Que a mayor abundamiento no se divisa en las normas de las leyes 19.378 y 18.883 el organismo competente para que pueda recurrir una persona que sea vulnerada en sus derechos laborales, con la sola salvedad de la Contraloría General de la República, según su artículo 156 de la Ley 18.883, ente que en todo caso no es un órgano jurisdiccional. Y por lo tanto si solo se aplicara esta normas las personas que ven afectados sus derechos laborales no podrían recurrir a un órgano jurisdiccional lo que sería atentatorio del debido proceso legal y de las normas constitucionales que rigen nuestro ordenamiento jurídico".

El fallo recién transcrito -limitado por la causal invocada en el recurso de nulidad-solo se avoca a estudiar la competencia del tribunal de primera instancia. Sin embargo, parte de ciertos supuestos sobre los cuales no detiene su análisis transformándose en verdaderos obiter dicta: a) que la relación entre un funcionario de la salud y la corporación municipal de la cual depende es una relación de trabajo que se materializa en un contrato de trabajo, y que por lo tanto la cuestión debatida es de aquellas que señala el artículo 420 del Código del Trabajo; b) que el artículo 48 de la Ley No 19.378 regula la terminación de la relación laboral estableciendo las causales del término del contrato. Sostiene el fallo que el funcionario de la atención primaria de la salud municipal dependiente de una corporación municipal es un trabajador y como tal el Código del Trabajo resulta perfectamente aplicable a la cuestión suscitada.

Pese a que el Estatuto de los Funcionarios de la Atención Primaria prevé la indemnización solo para un caso, que no es precisamente el tratado en la sentencia, la sentencia rechaza el recurso y por lo tanto da lugar a la indemnización por años de servicio requerida por el demandante. Así, aplica supletoriamente el artículo $1^{\circ}$ del Código del Trabajo, pretendiendo llenar un vacío que no es tal, dado que el legislador no ha establecido indemnizaciones para el resto de los casos del artículo 48 de la Ley No 19.378. El fijarla solo para uno de esos casos no significa necesariamente que ello implica una omisión y por lo tanto un vacío de ley. Además, es fundamental considerar la frase final del artículo 1 del Código del Trabajo, que permite la aplicación de este cuerpo normativo siempre y cuando esta no resulte contraria al estatuto especial de que se trata. Esto quiere decir que la aplicación del Código del Trabajo no puede importar la desnaturalización de la norma especial principal.

La Excelentísima Corte suprema ${ }^{26}$ ha sostenido que:

"[E]n la especie no puede recibir aplicación supletoria el Código del Trabajo, en su carácter de derecho común laboral, en la forma contemplada en el inciso tercero del

\footnotetext{
26 Corte Suprema, 30 de octubre de 2007, autos Rol No 6717-06. "Rojas Berríos, Laura Verónica con Corporación de Educación y Salud de Las Condes”. Disponible en http://www.poderjudicial.cl
} 
artículo $1^{\circ}$ de este cuerpo legal, con arreglo al cual los trabajadores de la administración estatal, entre otros personales indicados en su inciso segundo, se sujetan a las normas del mismo Código en los aspectos o materias no regulados en sus respectivos estatutos, siempre que ellas no fueren contrarias a estos últimos. Efectivamente, como ha quedado expuesto, el término de los servicios de un funcionario que se desempeña en la Atención Primaria de Salud Municipal, por vencimiento del plazo del contrato, es una causal específica de cesación en el cargo regulada precisamente en las normas estatutarias a que está sometido ese personal, lo que excluye la posibilidad de que ella se rija subsidiariamente por las disposiciones del Código referido”.

En el considerando decimotercero se lee:

"Que de lo anterior se sigue que en la medida que a la actora se le aplicaban directamente las normas sobre cesación de funciones contenidas en la Ley No 19.378, la autoridad municipal pudo hacer efectiva en su situación la causal prevista en la letra c) del artículo 48 de este Estatuto, que dice que los funcionarios de una dotación municipal dejarán de pertenecer a ella, entre otros motivos, por la llegada del plazo de vencimiento del contrato".

Por su parte, en el considerando decimocuarto se afirma:

"Que los razonamientos expuestos llevan a concluir que la sentencia impugnada por el recurso de autos cometió el error de derecho que este denuncia, al concluir que el despido de la actora fue injustificado y reconocerle el derecho a recibir las prestaciones que reclamaba en su demanda, sobre la base de una defectuosa aplicación de las disposiciones de los artículos 159, 163 y 168 del Código del Trabajo, puesto que tales preceptos no regían directa ni supletoriamente la terminación de los servicios de la demandante, la que, en cambio, se hallaba sujeta por entero y preferentemente a las reglas de las Leyes No 19.378 y No 18.883 , ya relacionadas".

En otro fallo más reciente la Excelentísima Corte Suprema ${ }^{27}$ a propósito del tema ha indicado que "efectivamente, la aplicación supletoria del Código Laboral a funcionarios de la administración municipal tiene lugar únicamente en los aspectos o materias no reguladas por los estatutos a que ellos están afectos, pero ello es siempre que las normas del Código no sean contrarias a tales estatutos, con arreglo a lo que dispone la parte final del inciso tercero del artículo $1^{\circ}$ de este texto" (Considerando octavo). A mayor abundamiento el mismo fallo señala que: "es útil considerar la distinta naturaleza que poseen el régimen establecido por el Código del Trabajo y el sistema estatutario como normativas reguladoras de las relaciones entre empleadores particulares y sus dependientes y el Estado y sus funcionarios, respectivamente". (Considerando décimo). En este sentido indica que:

27 Corte Suprema, 9 de junio de 2010, autos Rol No 1519-2010 "Márquez Pauchard, Verónica con Corporación Municipal de San Bernardo". Disponible en http://www.poderjudicial.cl 
"En cambio, el régimen estatutario es de carácter legal, ya que es la ley la que exclusivamente regula la situación de los funcionarios y señala la forma como nace y se extingue su relación con el Estado. Este sistema no tiene origen ni naturaleza convencional, ya que es el legislador el que determina por completo los derechos y obligaciones que son efectos de esa relación. Esta nace del acto unilateral de la autoridad que incorpora a un individuo a la dotación de un servicio público, en que la voluntad de este último solo interviene para aceptar su designación, pero no concurre a establecer las condiciones de la vinculación, ni los derechos y obligaciones de las partes, ya que todos estos elementos son fijados única y definitivamente por la ley en el estatuto que rige a ese personal". (Considerando duodécimo).

\section{CONSIDERACIONES FINALES}

1. El funcionario que labora en la atención primaria de salud dependiente de una corporación municipal es un funcionario cuyo estatus tiene como elementos principales y definitorios por un lado su sometimiento a las normas de la Ley No 19.378 y supletoriamente a la Ley No 18.883. La naturaleza de la relación de estos funcionarios es estatutaria y no convencional como lo ha indicado la Corte de Apelaciones en la sentencia autos Rol No 224-2011 de fecha 10 de mayo de 2011, la Corte Suprema en la sentencia autos Rol No 6717-2006 de fecha 30 de octubre de 2007 y en la sentencia autos Rol No 1519-2010 de fecha 9 de junio de 2010.

2. Es indiscutible que los funcionarios de la atención primaria de la salud municipal dependientes de una corporación municipal son funcionarios públicos. En primer lugar por una razón de texto, ya que el propio legislador le da tal calidad en el artículo 4 de la Ley No 19.378 ya tantas veces citada. En segundo lugar, la historia fidedigna de la ley también da cuenta de esta calidad, estableciendo como norma supletoria el estatuto administrativo de los funcionarios municipales y no el Código del Trabajo. En tercer lugar, porque luego de la sentencia del Tribunal Constitucional que impidió la creación de estas instituciones tales servicios quedaron radicados en las municipalidades. En cuarto lugar, porque el tratamiento que les da la Ley No 19.378 es idéntico al que reciben los funcionarios públicos sometidos a los estatutos administrativos (básicamente el general y el municipal), entre otras cuentan con una carrera funcionaria, son calificados, ingresan a la dotación previo concurso público, etc. En quinto lugar, sus remuneraciones son pagadas con fondos públicos. Por último, ellos desarrollan un servicio público.

3. La posición de la Contraloría General de la República y de la Dirección del Trabajo respecto de la calidad jurídica de los funcionarios no se ajusta ni al texto de la ley ni a la historia fidedigna de su establecimiento. Apartándose -además- del concepto funcional para definir un servicio como público, el que tal como indica su nombre atiende a la función que se presta como elemento preponderante por sobre el concepto orgánico.

4. No obstante se sostenga que las corporaciones municipales son entidades de derecho privado regido por sus estatutos y por las normas del Código Civil, es incuestionable que desarrollan un servicio público. Al menos debe afirmarse que se trata de instituciones anómalas, propias de la llamada Administración invisible del Estado, que están en el límite de lo público y lo privado, y donde está enteramente desaconsejado huir del derecho público. 
5. El hecho que los funcionarios de la salud municipal dependientes de una corporación sean funcionarios públicos no los libera de su sometimiento a las normas del Código del Trabajo cuando existe un genuino vacío legal (las meras omisiones del legislador no necesariamente constituyen un vacío legal). Como ha querido demostrarse en este trabajo, en materia de cesación del vínculo y su régimen de indemnizaciones no es posible sostener que exista verdaderamente un vacío legal.

\section{BIBLIOGRAFÍA}

ANDRADE Olivares, Lorenzo. Estatuto Docente en su faceta de estatuto administrativo de derecho público. Santiago: Editorial Thomson Reuters PuntoLex, 2009.

BINDER Rosas, Jaime. La laboralización de la Función pública y la nueva gestión pública. Santiago: Boletín Oficial de la Dirección del Trabajo, julio 2002.

IzQuierdo Hernández, Francisco; Molina García, Mónica. La Laboralización de los funcionarios públicos. Valencia, España: Editorial Tirant lo Blanch, 1996.

Sentencia Corte de Apelaciones de Santiago, 14 de enero de 2010, autos Rol No 36-2009, "Morales Maldonado, Mónica con Corporación de Educación y Salud de Las Condes”. Disponible en http://www.poderjudicial.cl.

Sentencia Corte de Apelaciones de Antofagasta, 10 de mayo de 2011, autos Rol No 224-2010, "Sornoza García, Robert con Corporación Municipal de Desarrollo Social de Antofagasta. Disponible en http://www.poderjudicial.cl.

Sentencia Corte de Apelaciones de Antofagasta, 26 de abril de 2011, autos Rol No 19-2011, "Ahumada Barraza, Sandra con Corporación Municipal de Desarrollo Social de Calama. Disponible en http://www.poderjudicial.cl.

Sentencia Tribunal Constitucional, 29 de febrero de 1988, apropósito del trámite de control de Constitucionalidad del proyecto de Ley Orgánica Constitucional de Municipalidades. Disponible en http://www. tribunalconstitucional.cl.

Sentencia Primer Juzgado de letras del Trabajo de Santiago, 15 de octubre de 2009, autos RIT No 0-103-2009, "Morales Maldonado, Verónica con Corporación de Educación y Salud de Las Condes". Disponible en http://www.poderjudicial.cl

Corte Suprema 30 de octubre de 2007, autos Rol No 6717-06, "Rojas Berríos, Laura Verónica con Corporación de Educación y Salud de Las Condes”. Disponible en http://www.poderjudicial.cl.

Corte Suprema, 9 de junio de 2010, autos Rol No 1519-2010, "Márquez Pauchard, Verónica con Corporación Municipal de San Bernardo”. Disponible en http://www.poderjudicial.cl

Contraloría General de la República, dictamen No 43.720, 16 de septiembre de 2008. Disponible en http:// www.contraloria.cl.

Contraloría General de la República, dictamen No 18547, 10 de junio de 1996. Disponible en http://www.contraloria.cl.

Contraloría General de la República, dictamen No 37.260, 8 de agosto de 2008. Disponible en http://www. contraloria.cl.

Contraloría General de la República, dictamen No 44.103, 15 de septiembre de 2006. Disponible en http:// www.contraloria.cl.

Contraloría General de la República, dictamen No 35.122, 6 de noviembre de 1995. Disponible en http://www. contraloria.cl.

Dictamen de la Contraloría General de la República No 61.847, 26 de diciembre de 2006. Disponible en http:// www.contraloria.cl. 
Carla Pietroboni Fuster / La laboralización de la función pública: la cesación del vínculo de los funcionarios de la atención primaria de la salud ...

Dirección del Trabajo, dictamen No 2140/150, 14 de mayo de 1998. Disponible en http://www.dt.gob.cl.

Dirección del Trabajo, dictamen No 3994/056, 8 de octubre de 2009. Disponible en http://www.dt.gob.cl.

Dirección del Trabajo, dictamen No 6598/298, 28 de noviembre de 1996. Disponible en http://www.dt.gob.cl.

Dirección del Trabajo, dictamen No. 1246/69, 18 de abril de 2002. Disponible en http://www.dt.gob.cl.

Dirección del Trabajo, dictamen No 2164/94, 25 de mayo de 2004. Disponible en http://www.dt.gob.cl.

Historia de la Ley No 19.378. Compilación de textos oficiales del debate parlamentario. Santiago, 1997. 